\title{
Anti Proliferative Properties of Melissa officinalis in Different Human Cancer Cells
}

\author{
Akram Jahanban-Esfahlan ${ }^{1}$, Sina Modaeinama ${ }^{2}$, Mozhgan Abasi ${ }^{3}$, Mehran \\ Mesgari Abbasi ${ }^{4}$, Rana Jahanban-Esfahlan ${ }^{3,5 *}$
}

\begin{abstract}
Background: Medicinal plants, especially examples rich in polyphenolic compounds, have been suggested to be chemopreventive on account of their antioxidative properties. Melissa officinalis L. (MO), an aromatic and medicinal plant, is well known in thios context. However, toxicity against cancer cells has not been fully studied. Here, we investigated the selective anticancer effects of an MO extract (MOE) in different human cancer cells. Materials and Methods: a hydro-alcoholic extract of MO was prepared and total phenolic content (TPC) and total flavonoid content (TFC) were determined by colorimetric assays. Antioxidant activity was determined by DPPH radical scavenging activity. MTT assays were used to evaluate cytotoxicity of different doses of MOE (0,5, $20,100,250,500,1000 \mu \mathrm{g} / \mathrm{ml}$ ) towards A549 (lung non small cell cancer cells), MCF-7 (breast adenocarcinoma), SKOV3 (ovarian cancer cells), and PC-3 (prostate adenocarcinoma) cells. Results: Significant $(\mathbf{P}<0.01)$ or very significant $(\mathrm{P}<0.0001)$ differences were observed in comparison to negative controls at all tested doses $(5-1000$ $\mu \mathrm{g} / \mathrm{ml})$. In all cancer cells, MOE reduced the cell viability to values below $33 \%$, even at the lowest doses. In all cases, $\mathrm{IC}_{50}$ values were below $5 \mu \mathrm{g} / \mathrm{ml}$. The mean growth inhibition was $73.1 \%, 86.7 \%, 79.9 \%$ and $77.8 \%$ in SKOV3, MCF-7 and PC-3 and A549 cells, respectively. Conclusions: Our results indicate that a hydro-alcoholic extract of MO possess a high potency to inhibit proliferation of different tumor cells in a dose independent manner, suggesting that an optimal biological dose is more important than a maximally tolerated one. Moreover, the antiprolifreative effect of MO seems to be tumor type specific, as hormone dependant cancers were more sensitive to antitumoral effects of MOE.
\end{abstract}

Keywords: MOE - A549 - SKOV3 - MCF-7 - PC-3 - anti proliferative effects

Asian Pac J Cancer Prev, 16 (14), 5703-5707

\section{Introduction}

Lemon balm, M. officinalis L. is one of the most used medicinal plants in Asia, Europe and the Mediterranean region. This plant is well known as a herbal tea for its aromatic, digestive and antispasmodic and sedative properties. The leaves emit a special fragrant lemon odour when bruised (Encalada et al., 2011). The chemical composition is essential oil, polyphenolic compounds: caffeic acid derivatives in large quantities, as well as Rosmaric Acid (RA), trimeric compounds and also some flavonoids such as luteolin-7-0-glucoside. Essential oil is considered to be the therapeutic principle mainly responsible for most of the activities mentioned; but plant phenolics, especially RA, are involved as well. The methanolic extracts of MO are more effective than aqueous extracts in term of neurological activities. (De Sousa et al., 2004; Encalada et al., 2011; Saraydin et al., 2012).

There are handful studies that evaluated antitumoral effects of MOE on a series of human cancer cells. In study by Encalada in 2011, the authors investigated the antiprolifreative effects of different fraction of $50 \%$ ethanolic and aqueous extract of MO on HCT-116 (human colon cancer cells) by MTT and NR assay. The $50 \%$ ethanolic extract showed significant differences after $72 \mathrm{~h}$ of treatment, reducing cell proliferation to values close to $40 \%$, even the lowest dose tested $(5 \mu \mathrm{g} / \mathrm{ml})$. In the MTT assay, the same extract caused the lowest cell viability with $13 \%$ at a concentration of $1,000 \mu \mathrm{g} / \mathrm{ml}$ after $72 \mathrm{~h}$ of treatment. Bioassay guided fractionation led to the isolation of an anti-proliferative compound, rosmarinic acid. In this study, the potent cytotoxic effects of MOE against HCT-116 cells was attributed to the presence of high amount of rosmarinic acid $(1,000 \mu \mathrm{g} / \mathrm{ml})$.

In another study by Saraydin et al in 2012, the authors investigated antitumoral effects of Melissa officinalis from Turkey on breast cancer cell lines (MCF-7, MDA-MB-468 and MDA-MB-23) in Vitro and in Vivo. In vitro apoptosis studies were performed by annexin $\mathrm{V}$ staining and flow cytometry analyses. Immunohistochemistry for $\mathrm{Ki}-67$ and

${ }^{1}$ Department of Nursing,Faculty of Maragheh, ${ }^{2}$ Department of Pharmacology and Toxicology, Faculty of Veterinary Medicine, Urmia University, Urmia, ${ }^{3}$ Department of Medical Biotechnology, Faculty of Advanced Medical Sciences, ${ }^{4}$ Drug Applied Research Center, ${ }^{5}$ Student Research Committee, Tabriz University of Medical Sciences, Tabriz, Iran*For correspondence: jahanbanr@tbzmed.ac.ir 


\section{Reza Gahremani et al}

caspase 7 in the tumoral tissue sections of DMBA-induced mammary tumors in rats was also performed, along with TUNEL assays to detect apoptotic cells. MOE possessed cytotoxicity against three cancer cell lines, inducing increase in Annexin-positive cells. Moreover, MOE induced a significant reduction in the viability of MCF-7, MDA-MB-468, MDA-MB-231 cells in a dose-dependent manner. Crude extracts of MO showed cytotoxicity to three cancer cell lines with $\mathrm{IC}_{50}$ values $18 \pm 2.0 \mu \mathrm{g} / \mathrm{mL}$, $17 \pm 1.4 \mu \mathrm{g} / \mathrm{mL}, 19 \pm 1.8 \mu \mathrm{g} / \mathrm{mL}$, respectively. Expression of caspase-7 protein and TUNEL positive cells were much higher in rats treated by MO, compared with the untreated control group, while expression of Ki-67 was decreased. Furthermore, in vivo studies showed that mean tumor volume inhibition ratio in MO treated group was $40 \%$ compared with the untreated rats. These results indicated that MO extracts have antitumoral potential against breast cancer (Saraydin et al., 2012).

In the course of our interest in biological applications and toxicity profile of this plant, this paper focused on study of the anti-proliferative activity of methanolic extract of Melissa officinalis from Iran on different human cancer cells.

\section{Materials and Methods}

\section{Preparation of Extracts}

Plant collected from Tabriz, East Azerbaijan Province, Iran, in Jun 2014. The Leaves were shade dried and grinded into powder with mortar and pestle. The prepared powder was kept in tight containers protected completely from light. Extraction of hydroalcoholic extract (HAE) was carried out according to previous protocols (Sineh Sepehr et al., 2012; Valiyari et al., 2013) by macerating $100 \mathrm{~g}$ of powdered dry plant in $500 \mathrm{~mL}$ of $80 \%$ ethanol for $48 \mathrm{~h}$ at room temperature. Then, the macerated plant material was extracted with $80 \%$ ethanol solvent by percolator apparatus (2-liter volume) at $25 \mathrm{c}$. The plant leaves extract was removed from percolator, filtered through Whatman filter paper (NO. 4), and dried under reduced pressure at $37^{\circ} \mathrm{C}$ with rotatory evaporator. The concentrated leaves extracts of the plant were dissolved in Phosphate Buffer Saline (PBS) and was filtered to obtain a stock solution of $10 \mathrm{mg} / \mathrm{mL}$. Subsequently, the substocks with concentrations ranging from $5-1000 \mu \mathrm{g} / \mathrm{ml}$ was prepared from stock and further used in MTT assay.

\section{Determination of Total phenolic content (TPC)}

Total phenolic content was determined with FolinCiocalteu Reagent (FCR) according to the a described method (Singleton and Rossi, 1965) with some modifications. Briefly, $0.5 \mathrm{ml}$ of each phenolic extract was mixed with $2 \mathrm{ml}$ of $7.5 \%$ sodium carbonate, and then the mixture was allowed to stand at room temperature for $2 \mathrm{~min}$. After addition of $2.5 \mathrm{ml}$ ten-fold Folin-Ciocalteu reagent, the mixture was incubated in the dark room for $30 \mathrm{~min}$. The absorbance was measured at $720 \mathrm{~nm}$ by using a spectrophotometer. The results were expressed as equivalent $\mathrm{mg}$ of Gallic acid per $100 \mathrm{~g}$ of fresh mass (mg GAE/100 g FM). A standard curve for Gallic acid was plotted under the same conditions as the studied samples.
All determinations were performed in triplicates.

\section{Determination of Total flavonoid content (TFC)}

Total flavonoid content of the extracts were assayed by the colorimetric method described by other authors (Zhishen et al., 1999; Jahanban-Esfahlan et al., 2012), with minor modifications. CME $(250 \mu \mathrm{l})$ was mixed with 1.25 $\mathrm{ml}$ of distilled water and $75 \mu \mathrm{l}$ of a $5 \% \mathrm{NaNO}_{2}$ solution. After five minutes, $150 \mu \mathrm{l}$ of a $10 \% \mathrm{AlCl} 3 . \mathrm{H}_{2} \mathrm{O}$ solution, $500 \mu \mathrm{l}$ of $1 \mathrm{M} \mathrm{NaOH}$ and $275 \mu \mathrm{l}$ of distilled water were added to the mixture. The absorbance of the mixture was measured at $507 \mathrm{~nm}$. The results were expressed as equivalent $\mathrm{mg}$ of Qurcetin per $100 \mathrm{~g}$ of fresh mass (mg Q/100 g FM) and compared with the Qurcetin standard curve, which was made under the same conditions. All determinations were performed in triplicates.

\section{DPPH free radical scavenging activity}

The DPPH radical scavenging activity was determined as described methods (Brand-Williams et al., 1995) with some modifications. Various volumes of extracts (30, 50, 70 and $100 \mathrm{~mL}$ ) were added to $1 \mathrm{~mL}$ of 2 , 2-diphenyl-1-picrylhydrazyl (DPPH) solution (0.1 mM in methanol) and the reaction mixture shaken vigorously. After incubation at room temperature for $10 \mathrm{~min}$, the absorbance of this solution was determined at $517 \mathrm{~nm}$, by using a spectrophotometer. The antioxidant activity was expressed as $\mathrm{IC}_{50}$ values, which were calculated by nonlinear regression with a one phase exponential association equation using GraphPad Prism version 6.0.

\section{Cell culture}

SKOV3 (human ovarian carcinoma), MCF-7(human breast adenocarcinoma), PC-3 (Human prostate adenocarcinima), A549 (lung non small cell cancer cells) were obtained from the Pasture Institute (Tehran- Iran ). Cells were grown in RPMI 1640 supplemented with $10 \%$ heat-inactivated fetal bovine serum (FBS), penicillin $(10 \mathrm{U} / \mathrm{ml})$, streptomycin $(10 \mu \mathrm{g} / \mathrm{ml})$ and $0.2 \mathrm{mM}$ sodium pyruvate. Cultures were incubated in the presence of $5 \%$ $\mathrm{CO}_{2}$ at $37^{\circ} \mathrm{C}$ and $100 \%$ relative humidified at MOsphere.

\section{MTT assay}

The cells were seeded in 96-well plates with a density of $1 \times 10^{4}$ cells/well $/ 200 \mathrm{~mL}$ and incubated for $24 \mathrm{~h}$ at $37^{\circ} \mathrm{C}$ and $5 \% \mathrm{CO}_{2}$. The cells were treated with different concentrations of solvent extracts $(5,20,100,250,500$, $1000 \mu \mathrm{g} / \mathrm{ml}$ ). Paclitaxel (plant-derived chemotherapeutic anti-cancer drug from Taxus brevifolia) was used as a positive control. Untreated cancer cells was used as negative control $(0 \mu \mathrm{g} / \mathrm{ml}$, vehicle alone). After $72 \mathrm{~h}$ treatment, $10 \mathrm{~mL}$ of MTT reagent was added to each well. The plates were incubated at $37^{\circ} \mathrm{C}$ and $5 \% \mathrm{CO}_{2}$ for $4 \mathrm{~h}$. Then, $100 \mathrm{~mL}$ of the solubilization solution was added to each well and followed by incubation overnight at 37 $\mathrm{C}$ to dissolve formazan crystals. Finally, absorbance was read using an ELISA plate reader at a wavelength of 570 $\mathrm{nm}$. The percentage of cytotoxicity and cell viability were calculated using following equation: \% Cytotoxicity $=1-$ (mean absorbance of treated cells/mean absorbance of negative control) and \% Viability $=100$ - \% Cytotoxicity. 


\section{Statistical analysis}

All the data represented in this study are mean \pm SEM of three identical experiments made in three replicate. Statistical significance was determined by analysis of variance, followed by LSD test and p-value $\leq 0.01$ was considered significant. All analyses were conducted using the SPSS 16.

\section{Results and Discussion}

In the recent decades, although so much success accomplished in cancer treatment, however it still remains among the most common killers in the world (Jahanban Esfahlan et al., 2011). universal cancer burden rises to 14.1 million new cases in 2012 and striking increase in breast cancers must be addressed. Furthermore, according to the 2014 cancer statistics in United Sates, Among men, cancers of the prostate, lung and bronchus, and colorectum will account for about $50 \%$ of all newly diagnosed cancers, as prostate cancer alone will account for $27 \%(233,000)$ of incident cases in men. At the other hand, cancers of breast, lung and bronchus, and colorectum, accounting for one-half of all cases in women. Breast cancer alone is expected to account for $29 \%(232,670)$ of all new cancers among women. Overall, cancers of the lung and bronchus, prostate, breast, and colorectum continue to be the most common causes of cancer death. These 4 cancers account for almost half of the total cancer deaths among men and women, with more than one-quarter of all cancer deaths due to lung cancer. An urgent need in cancer control today

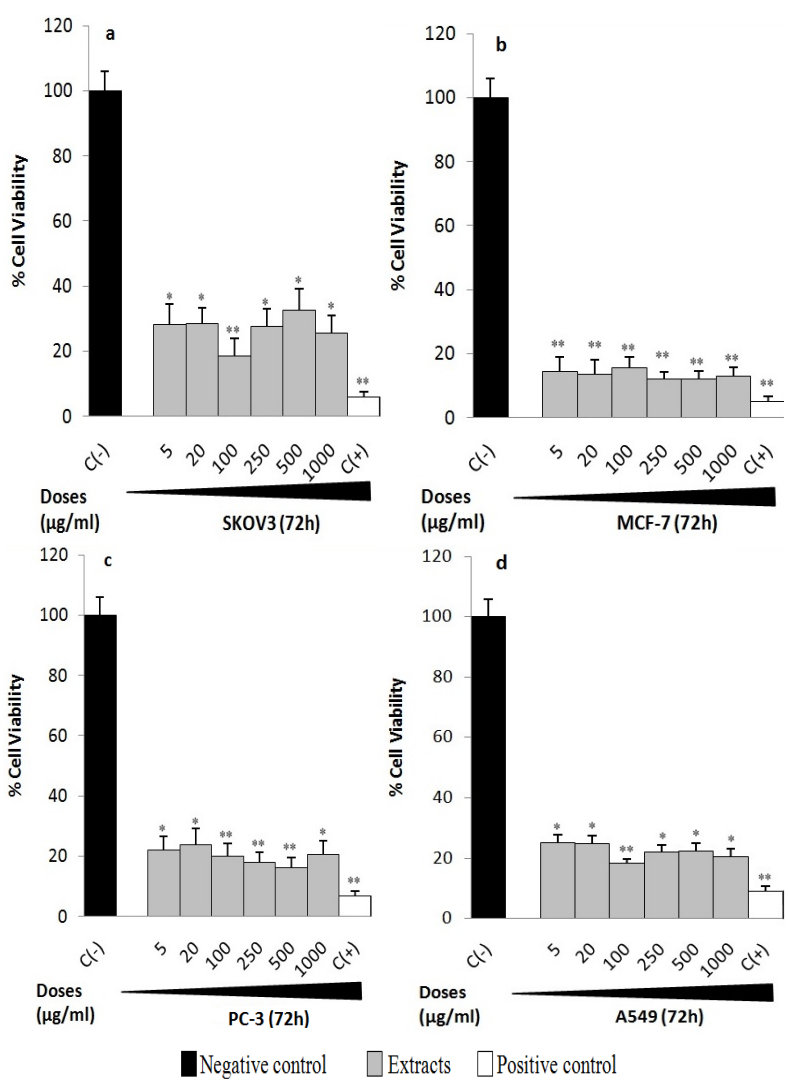

Figure 1. MO Extract Inhibit Different Human Cancer Cell Proliferation. *p<0.01; **p<0.001, compared to the negative control is to develop effective and affordable approaches to the early detection, diagnosis, and treatment of cancer (Abbasi et al., 2014b; Siegel et al., 2014).

Among a plethora of options for cancer treatment and prevention, natural products especially those rich in antioxidants, have always being regarded as a safe agents that effectively could scavenge the free radicals and so protect cells form their hazardous effects (JahanbanEsfahlan et al., 2010; Abbasi et al., 2014c). In this way, Melissa Officinalis shows a high content for divergent polyphenolic and flavonoid compounds.

In study by Encalada, et al in 2011, Hydroalcholic (HAE) and Aqueous extract (AQE) of MO from Barcelona-Spain were analyzed. For AQE, \% TPC was determined as 1,980.54 mg/100 g FM and \% TFC was determined $627 \mathrm{mg} / 100 \mathrm{~g}$ FM. DPPH $\mathrm{IC}_{50}$ was $17.11 \mu \mathrm{g} /$ $\mathrm{ml}$. For HAE, \% TPC was determined as $3407.32 \mathrm{mg} / 100$ g FM and \% TFC was determined $927 \mathrm{mg} / 100 \mathrm{~g} \mathrm{FM.}$ DPPH IC I0 $_{50}$ was $11.01 \mu \mathrm{g} / \mathrm{ml}$ (Encalada et al., 2011). Hydroalcholic extract (HAE) of MO from Azerbaijan, Iran cultivators showed a considerable amount of \% TFC and \%TPC comparable to that of Spain Cultivators. In this way, TFC was determined $415.7 \mathrm{mg} \mathrm{Q} / 100 \mathrm{~g}$ FM and \% TPC was $1506.713 \mathrm{mg} \mathrm{GAE} / 100 \mathrm{~g}$ FM. The antioxidant capacity is described quantitatively by the concentration

A

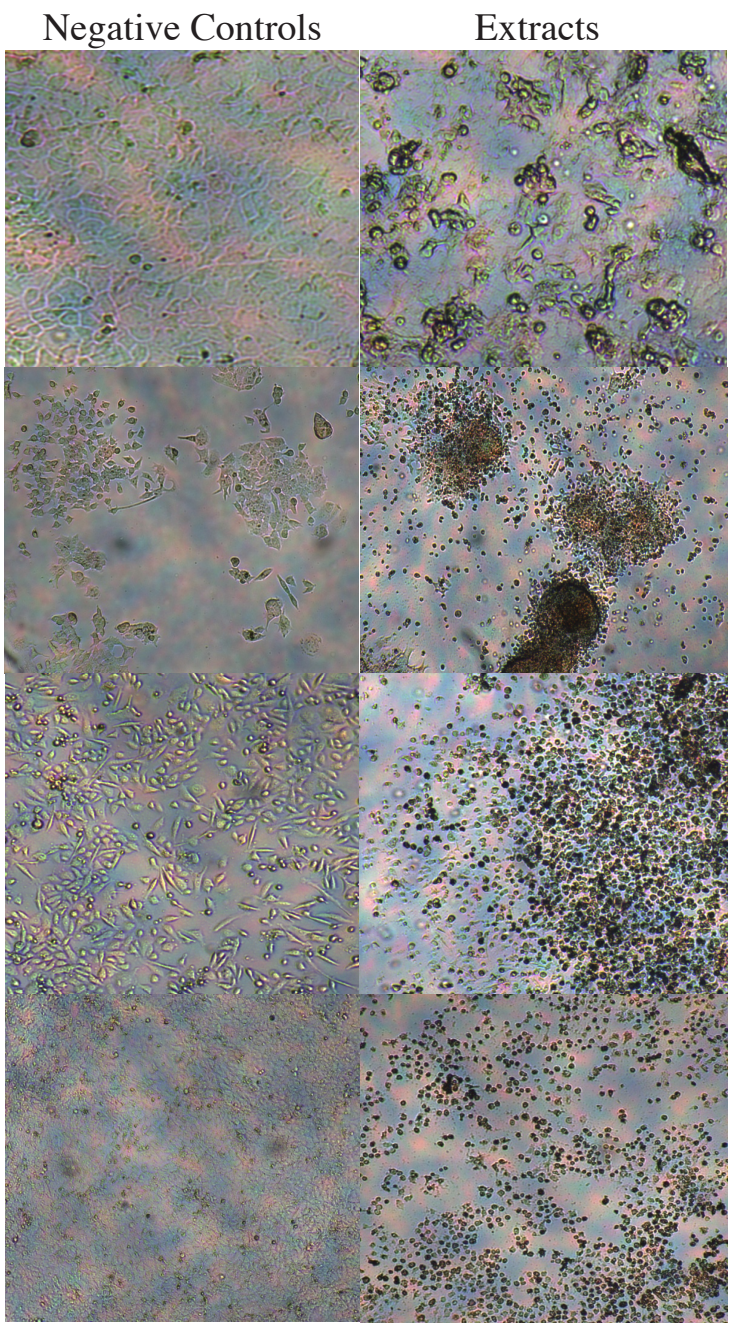

Figure 2. Cytotoxic Effect of MOE on Human SKOV3 (a), MCF-7 (b), PC-3(c) and A549 (d) Cell Lines after 72h Exposure 
Reza Gahremani et al

Table 1. Growth Inhibition (72 h)

\begin{tabular}{lllll}
\hline $\begin{array}{l}\text { Doses } \\
(\mu \mathrm{g} / \mathrm{ml})\end{array}$ & SKOV3 MCF-7 PC-3 & A549 & \\
\hline 1000 & $74.5 \pm 5.2$ & $87.25 \pm 4.2$ & $79.6 \pm 5.2$ & $79.46 \pm 5.1$ \\
500 & $67.29 \pm 5.5$ & $88.12 \pm 6.6$ & $83.7 \pm 3.0$ & $77.45 \pm 4.3$ \\
250 & $72.4 \pm 4.8$ & $88.08 \pm 5.4$ & $82.0 \pm 6.4$ & $78.04 \pm 4.1$ \\
100 & $81.3 \pm 6.1$ & $84.5 \pm 8.3$ & $80.0 \pm 8.1$ & $81.58 \pm 4.9$ \\
20 & $71.4 \pm 8.2$ & $86.54 \pm 5.4$ & $76.29 \pm 5.2$ & $75.16 \pm 3.7$ \\
5 & $71.7 \pm 7.6$ & $85.6 \pm 4.3$ & $78.0 \pm 7.1$ & $74.87 \pm 3.4$ \\
Mean \pm SEM & $73.09 \pm 4.4$ & $86.67 \pm 1.1$ & $79.93 \pm 3.7$ & $77.8 \pm 4.7$ \\
\hline
\end{tabular}

of antioxidant required to scavenge $50 \%$ of $\mathrm{DPPH} \bullet$, which is referred as $\mathrm{IC}_{50}$. This value was obtained from the graph of the percentage of scavenged radical versus the concentration of antioxidant. There is a reverse relation between DPPH $\mathrm{IC}_{50}$ and TPC and TFC. In our study, DPPH IC50 was obtained at $2.9 \mu \mathrm{g} / \mathrm{ml}$ which indicates to the high antioxidant activity of Persian MOE compared to MO extract from Spain. In course of our interest on toxicological properties of different medicinal plants towards aggressive tumors(Abbasi et al., 2014a), in following study, we investigated the selective cytotoxicity of MO extract on a series of human cancers including ovarian cancer cells (SKOV3), breast adenocarcinoma cells (MCF-7), prostate adenocarcinoma cells (PC-3) and lung non small cancer cells (A549) by MTT assay. In course our interest on treatment of aggressive tumors; we specially selected these cancer cells because each displays a high propensity for metastasis in vivo. It is shown that MCF-7 cells form tumors when injected into athymic nude mice. These tumors are able to metastasize to lungs, liver and spleen. MCF-7 cells secrete into the culture media collagenases able to lyse types I and IV collagens(Shafie and Liotta, 1980). At the other hand, PC-3 cells have high metastatic potential to bone compared to other prostate cell lines such as DU145 cells which have a moderate metastatic potential and to LNCaP cells which have low metastatic potential (Sanchez-Sweatman et al., 1998). lung non small cell carcinoma is a rapid growth tumor with high propensity for invasion and metastasis. This cell line frequently use for induction of lung metastasis in mice (Shindo-Okada et al., 2002). Similar to MCF7 , SKOV3 cells are among the aggressive and also the most common gynecologic cancers in women, however the special behavior of SKOV3 differ it from other ER+ cancer cells such as MCF-7. Both MCF-7 and SKOV3 have the receptors for estrogen (ER+) and basically they proliferate in response to estrogen, however practically ER+SKOV3 cells are irresponsive to both estrogen and its analogues and this feature makes it a good candidate for studding the mechanism by which ER+ cells became unresponsive/resistence to estrogen and so antiestrogenenic therapies (Esfahlan et al., 2011). As some polyphenols and especially some well known flavonoids such as chrysin, genistein, and quercetin, could interfere with aromatase activity and so could hinder synthesis of estrogen which act as a main growth promoting factor on cancer cells(Gnoatto et al., 2008), so we used both hormone responsive and irresponsive cells to discern the selective effects of high polyphenolic extract of $\mathrm{MO}$ on these cells.

The results of following study showed that in all doses, significant or very significant difference was observed between treated and untreated controls in a dose independent manner (Figure 1,2). In all cell lines, $5 \mu \mathrm{g} /$ $\mathrm{ml}$ of $\mathrm{MO}$ extract resulted in $>50 \%$ growth inhibition in treated cells which account for the high toxicity profile of hyroalcoholic extract used in our study which requires a lower $\mathrm{IC}_{50}$ compared to other extracts (De Sousa et al., 2004; Encalada et al., 2011) (see also Table1).

In case of ovarian cancer cells, the maximum growth inhibition of $81.3 \%$ was obtained at doses $100 \mu \mathrm{g} / \mathrm{ml}$, value close to positive control $(20 \mu \mathrm{g} / \mathrm{ml}$ Toxol used as positive control and it caused to $93.76 \%$ growth inhibition of SKOV3 cancer cells) meanwhile dose $500 \mu \mathrm{g} / \mathrm{ml}$ of MO extract caused to the lowest growth inhibition of $67.29 \%$. The mean growth inhibition in these cells was $73.09 \%$.

In MCF-7 cancer cells, the maximum growth inhibition of $88.08 \%$ and $88.12 \%$ was obtained at doses $250 \mu \mathrm{g} / \mathrm{ml}$ and $500 \mu \mathrm{g} / \mathrm{ml}$, respectively, value comparable to that of $20 \mu \mathrm{g} / \mathrm{ml}$ Toxol which caused to $95.1 \%$ growth inhibition of MCF-7 breast adenocarcinoma cells. The lowest growth inhibition of $84.5 \%$ was obtained at dose $100 \mu \mathrm{g} / \mathrm{ml}$ of MO extract. The mean growth inhibition was $86.67 \%$.

In PC-3 prostate adenocarcinoma cells, $\mathrm{MO}$ extract caused to the maximum growth inhibition of $83.7 \%$ at doses $500 \mu \mathrm{g} / \mathrm{ml}$. In this cell line, $20 \mu \mathrm{g} / \mathrm{ml}$ Toxol caused to 93.1\% growth inhibition of PC-3 cancer cells meanwhile dose $20 \mu \mathrm{g} / \mathrm{ml}$ of MO extract caused to the lowest growth inhibition $76.29 \%$, respectively. The mean growth inhibition in these cells was $79.93 \%$ (Table1, Figure 2).

In case of A549 cancer cells, the maximum growth inhibition of $81.58 \%$ was obtained at dose $100 \mu \mathrm{g} / \mathrm{ml}$. $20 \mu \mathrm{g} / \mathrm{ml}$ Toxol caused to $90.25 \%$ growth inhibition of A549 cells. In these cells, dose $5 \mu \mathrm{g} / \mathrm{ml}$ caused to the lowest growth inhibition of $74.87 \%$. The mean growth inhibition in these cells was $77.8 \%$ (Table1, Figure 2).

In all cancer cells, $\mathrm{MO}$ extract reduced the cell viability to values below $33 \%$, even the lowest doses. In this regard, MCF-7 breast cancer cells were the most responsive cells to antiprolifreative effects of MOE with a maximum mean growth inhibition of $86.67 \%$ vs. $79.93 \%, 77.8 \%$ and $73.09 \%$ in PC-3, A549 and SKOV3 cells, respectively. It seemed that SKOV3 ovarian cancer cells were the least responsive cells to cytotoxic properties of MOE compared to the other studied cancer cells. This finding could be partly explained by different responsiveness of studied cancer cells to the anti-estrogenic activity of the rosmaric Acid (RA). The RA is one of the main constituents of HAE extract of MO and it could interfere with aromatase activity and so esterogen synthesis (Balunas et al., 2008). As SKOV3 cells are ER+ but their proliferation is not estrogen dependent, so these cells are least sensitive to antiprolifreative activity of MOE compared to other esterogen and androgen sensitive cancer cells including MCF-7, PC-3 and A549 cancer cells.

Our results indicated that hydoalcholic extract of MO possess a high potency to inhibit proliferation of different tumors cells in a dose independent manner, suggesting that an optimal biological dose is more important and relevant than a maximally tolerated one. Moreover, the 
antiprolifreative effects of MO seems to be tumor type specific, as hormone dependant cancer cells showed a high responsiveness to antitumoral effects of this extracts.

\section{Acknowledgements}

This study is funded by a grant from Student Research Committee (SRC),Tabriz, Iran.

\section{References}

Abbasi MM, Khiavi MM, Monfaredan A, et al (2014a). DOXMTX-NPs augment p53 mRNA expression in OSCC model in rat: effects of IV and oral routes. Asian Pac J Cancer Prev, 15, 8377-82.

Abbasi MM, Monfaredan A, Hamishehkar H, et al (2014b). New formulated "DOX-MTX-loaded nanoparticles" downregulate HER2 gene expression and improve the clinical outcome in OSCCs model in rat: the effect of IV and oral modalities. Asian Pac J Cancer Prev, 15, 9355-60.

Abbasi MM, Monfaredan A, Hamishehkar H, et al (2014c). Novel DOX-MTX nanoparticles improve oral SCC clinical outcome by down regulation of lymph dissemination factor VEGF-C expression in vivo: oral and IV modalities. Asian Pac J Cancer Prev, 15, 6227-32.

Balunas MJ, Su B, Brueggemeier RW, et al (2008). Natural products as aromatase inhibitors. Anticancer Agents Med Chem, 8, 646-82.

Brand-Williams W, Cuvelier M, Berset C (1995). Use of a free radical method to evaluate antioxidant activity. $L W T$-Food Science Technol, 28, 25-30.

De Sousa AC, Alviano DS, Blank AF, et al (2004). Melissa officinalis L. essential oil: Antitumoral and antioxidant activities. J Pharm Parmacol, 56, 677-81.

Encalada MA, Hoyos KM, Rehecho S, et al (2011). Antiproliferative effect ofmelissa officinalison human colon cancer cell line. Plant Foods Hum Nutr, 66, 328-34.

Esfahlan RJ, Zarghami N, Esfahlan AJ, et al (2011). The possible impact of obesity on androgen, progesterone and estrogen receptors (ERalpha and ERbeta) gene expression in breast cancer patients. Breast Cancer (Auckl), 5, 227-37.

Gnoatto SC, Dassonville-Klimpt A, Da Nascimento S, et al (2008). Evaluation of ursolic acid isolated from Ilex paraguariensis and derivatives on aromatase inhibition. Eur J Med Chem, 43, 1865-77.

Jahanban-Esfahlan A, Jahanban-Esfahlan R, jamei R, et al (2012). Morphology and physicochemical properties of 40 genotypes of almond (Amygdalus communisL.) fruits. Eur J Experimental Biol, 2, 2456-64

Jahanban- Esfahlan A, Jamei R, Jahanban- Esfahlan R (2010). The importance of almond (Prunus amygdalusL.) and its by-products. Food Chem, 349.

Jahanban Esfahlan R, Zarghami N, Rahmati-Yamchi M, et al (2011). Quantification of steroid receptors gene expression in breast cancer patients: possible correlation with serum level of adipocytokines. $J$ Cancer Therapy, 2, 659-65.

Sanchez-Sweatman OH, Orr FW, Singh G (1998). Human metastatic prostate $\mathrm{PC} 3$ cell lines degrade bone using matrix metalloproteinases. Invasion Metastasis, 18, 297-305.

Saraydin SU, Tuncer E, Tepe B, et al (2012). Antitumoral effects of Melissa officinalis on breast cancer in vitro and in vivo. Asian Pac J Cancer Prev, 13, 2765-70.

Shafie SM, Liotta LA (1980). Formation of metastasis by human breast carcinoma cells (MCF-7) in nude mice. Cancer Letters, 11, 81-7.

Shindo-Okada N, Takeuchi K, Han BS, et al (2002). Establishment of cell lines with high and low metastatic potential from A549 human lung adenocarcinoma. Jpn J Cancer Res, 93, 50-60.

Siegel R, Ma J, Zou Z, et al (2014). Cancer statistics, 2014. CA Cancer J Clin, 64, 9-29.

Sineh Sepehr K, Baradaran B, Mazandarani M, et al (2012). Studies on the cytotoxic activities of punica granatum 1 . var. spinosa (Apple Punice) extract on prostate cell line by induction of apoptosis. ISRN Pharm, 2012, 547942.

Singleton V, Rossi JA (1965). Colorimetry of total phenolics with phosphomolybdic-phosphotungstic acid reagents. Am $J$ Enol Viticulture, 16, 144-58.

Valiyari S, Jahanban-Esfahlan R, Zare Shahneh F, et al (2013). Cytotoxic and apoptotic activity of Scrophularia oxysepala in MCF-7 human breast cancer cells. Toxicol Environm Chem, 95, 1208-20.

Zhishen J, Mengcheng T, Jianming W (1999). The determination of flavonoid contents in mulberry and their scavenging effects on superoxide radicals. Food Chem, 64, 555-9. 